\title{
Candesartan ameliorates acute myocardial infarction in rats through inducible nitric oxide synthase, nuclear factor-кB, monocyte chemoattractant protein-1, activator protein-1 and restoration of heat shock protein 72
}

\author{
XUEFENG LIN ${ }^{1}$, MIN WU ${ }^{2}$, BO LIU ${ }^{3}$, JUNKUI WANG $^{3}$, GONGCHANG GUAN $^{3}$, \\ AIQUN MA ${ }^{1}$ and YONG ZHANG $^{3}$
}

\begin{abstract}
${ }^{1}$ Department of Cardiovascular Medicine, First Affiliated Hospital of Medical College of Xi'an Jiaotong University, Xi'an, Shaanxi 710061; ${ }^{2}$ Department of Endocrinology; ${ }^{3}$ First Department of Cardiology, Shaanxi Provincial People's Hospital, Third Affiliated Hospital of Medical College of Xi'an Jiaotong University, Xi'an, Shaanxi 710068, P.R. China
\end{abstract}

Received December 12, 2014; Accepted September 1, 2015

DOI: $10.3892 / \mathrm{mmr} .2015 .4432$

\begin{abstract}
Candesartan, an angiotensin II type 1 receptor antagonist, has a variety of biological activities, including antioxidant, anti-inflammatory and anticancer activities, with specific pharmacological effects. The present study investigated the mechanisms and protective effect of candesartan on acute myocardial infarction in rats. Male Wistar rats (8-week-old) were induced as a model of acute myocardial infarction and treated with candesartan $(0.25 \mathrm{mg} / \mathrm{kg})$ for 2 weeks. The present study first measured the activities of casein kinase $(\mathrm{CK})$, the MB isoenzyme of creatine kinase (CK-MB) and lactate dehydrogenase (LDH), the level of cardiac troponin T (cTnT) and infarct size. Subsequently, western blot analysis was performed to analyze the protein expression levels of inducible nitric oxide synthase (iNOS) and heat shock protein 72 (HSP72) in the rats. An enzyme linked immunosorbent assay was used to detect iNOS and nuclear factor- $\kappa \mathrm{B}(\mathrm{NF}-\kappa \mathrm{B})$ activity. In addition, gene expression levels of monocyte chemotactic protein-1 (MCP-1) and activating protein-1 (AP-1) were determined using reverse transcription-quantitative polymerase
\end{abstract}

Correspondence to: Mr. Aiqun Ma, Department of Cardiovascular Medicine, First Affiliated Hospital of Medical College of Xi'an Jiaotong University, 277 Yanta West Road, Xi'an, Shaanxi 710061, P.R. China

E-mail: aiqunma2014@163.com

Mr. Yong Zhang, First Department of Cardiology, Shaanxi Provincial People's Hospital, Third Affiliated Hospital of Medical College of Xi'an Jiaotong University, 256 West Friendship Road, Xi'an, Shaanxi 710068, P.R. China

E-mail: zhangyong971292@163.com

Key words: candesartan, acute myocardial infarction, inducible nitric oxide synthase, nuclear factor- $\kappa \mathrm{B}$, monocyte chemoattractant protein-1, activator protein-1, restoration of heat shock protein 72 chain reaction analysis. Finally, the activities of caspase- 3 and caspase- 9 were examined using colorimetric assay kits. In the serum of the rat model of acute myocardial infarction, candesartan significantly increased the activities of CK, CK-MB and $\mathrm{LDH}$, and the level of cTnT. The infarction size was perfected by candesartan treatment. Candesartan significantly reduced the protein expression and activity of iNOS, the activity of NF- $\kappa \mathrm{B}$ p 65, and the gene expression levels of MCP-1 and AP-1 in the rat model of acute myocardial infarction. Candesartan increased the protein expression of HSP-72 in the acute myocardial infarction rat model. However, candesartan did not effect the levels of caspase- 3 or caspase- 9 in the rat model of acute myocardial infarction. These results suggested that candesartan ameliorates acute myocardial infarction in rats through iNOS, NF- $\kappa$ B, MCP-1 and AP-1, and the restoration of HSP72.

\section{Introduction}

The mechanism underlying acute myocardial infarction involves the occurrence of atherosclerosis, followed by atherosclerotic plaque rupture, hemorrhage and thrombosis or coronary artery spasm, leading to complete or incomplete coronary occlusion (1). The recurrence and mortality rates of acute myocardial infarction are high in China, at $~ 10$ and $16 \%$, respectively. Following an initial myocardial infarction, the mortality rate of second relapse increases to $>38 \%$ (2).

Inducible nitric oxide synthase (iNOS) is important in angiogenesis and its generation. Nitric oxide generated by iNOS catalysis may, in addition to inducing endothelial cell migration and proliferation, mediate angiogenic action of growth factors, including vascular endothelial growth factor, fibroblast growth factor and transforming growth factor (3). Liu et al reported that tirofiban reduces the size of the no-reflow and infarct of acute myocardial infarction through suppression of iNOS activity (4). Zaitone et al provided evidence that rosuvastatin promotes angiogenesis in acute myocardial infarction via the control of iNOS in rats (5). 
Nuclear factor- $\kappa \mathrm{B}(\mathrm{NF}-\kappa \mathrm{B})$ is present in almost all cells, including neuronal and glial cells, as well as brain endothelial cells and other cells, which can be combined specifically with gene promoters or enhancer sequences of other cells to promote transcription and expression, and are closely associated to the inflammatory response, immune response, and the proliferation, differentiation and apoptosis of cells $(6,7)$. Sui et al suggested that huperzine A ameliorates the damage induced by acute myocardial infarction through inhibition of the expression of the NF- $\kappa \mathrm{B}$ subunit p65 in rats. Qiao et al demonstrated that anesthetic preconditioning protects rat hearts from ischemia/reperfusion (I/R) injury through the attenuation of $\mathrm{NF}-\kappa \mathrm{B}$ activation (8).

Monocyte chemotactic protein-1 (MCP-1) promoter sequence analysis has revealed that there is an activating protein-1 (AP-1) binding site in the promoter region and $\mathrm{NF}-\kappa \mathrm{B}$ binding sites, indicating that AP-1 activation is involved in regulating the expression of MCP-1 (9). Interleukin-1 $\beta$ (IL-1 $\beta$ ) induces the expression of MCP-1 through the activation of $\mathrm{NF}-\kappa \mathrm{B}$ and AP-1, while the proteasome inhibitor induces the expression of MCP-1 by the AP-1 signaling pathway (10). Valen et al reported that $\mathrm{NF}-\kappa \mathrm{B}$ and AP-1 regulate the inflammatory genes in the hearts of patients with unstable angina (11), and Xie et al suggested that activation of the AP-1 transcription pathway may be important in ventricular remodeling of myocardial infarction (12).

Several studies (13-15) have demonstrated the close association between heat shock protein 72 (HSP7) and myocardial protection, and the extent of HSP72 induction and myocardial protection intensity presents a positive correlation (13). However, as the induction of the endogenous expression of HSP72 requires sublethal stress, it cannot be used clinically (11). Tanonaka et al suggested that trandolapril increases tolerance against heat stress-induced deterioration of acute myocardial infarction through HSP72 and HSP73 (13), and Valen et al reported that unstable angina activates myocardial infarction through the activation of HSP72, and the suppression of $\mathrm{NF}-\kappa \mathrm{B}$ and AP-1 (11).

Candesartan is an angiotensin II receptor antagonist, belonging to diphenyl imidazole, with a similar effect to losartan. The binding force of candesartan with angiotensin receptor 1 is 80 times higher, compared with that of losartan $(16,17)$. Candesartan restores reperfusion injury through HSP72 in hereditary insulin-resistant rats (18). The present study aimed to estimate the potential effects of candesartan against acute myocardial infarction, examine whether candesartan can treat acute myocardial infarction and further investigate the mechanism underlying its effects.

\section{Materials and methods}

Drug administration. The chemical structure of candesartan (Sigma-Aldrich; purity 98\%) is indicated in Fig. 1, which was dissolved in physiological saline. The casein kinase (CK; cat. no. GA-PM0252MO; GenAsia Biotech, Co., Ltd., Shanghai China), the MB isoenzyme of creatine kinase (CK-MB; cat. no. E-EL-R1327c; Elabscience Biotechnology Co., Ltd., Wuhan, China), lactate dehydrogenase (LDH; cat. no. E-EL-R0338c, Elabscience Biotechnology Co., Ltd.) and cardiac troponin T (cTnT; cat. no. E-EL-R0151c;
Elabscience Biotechnology Co., Ltd.) commercial kits, and iNOS (cat. no. E-EL-R0520c; Elabscience Biotechnology Co., Ltd.), NF-кB p65 (cat. no. ybA467Ge; Shanghai Yantuo Biotechnology) and MCP-1 (cat. no. E-EL-R0633c, Elabscience Biotechnology Co., Ltd.) commercial enzyme linked immunosorbent assay (ELISA) kits were purchased from Beyotime Institute of Biotechnology (Nanjing, China). TRIzol reagent was purchased from Invitrogen Life Technologies (Carlsbad, CA, USA). A PrimeScript RT reagent kit was purchase from Takara Biotechnology, Co., Ltd. (Dalian, China). The Bicinchoninic Acid protein assay and caspase-3 and caspase-9 activities colorimetric kits were purchased from Sangon Biotech Co., Ltd. (Shanghai, China).

Animals. A total of 30 male Wistar rats (8-week-old; 280-300 g) were purchased from The Animal Center of Xi'an Jiaotong University, and animal experiments were performed in accordance with the Guide for the Care and Use of Laboratory Animals (19), and approved by the ethics committee of the Xi'an Jiaotong University (Xi'an, China). These rats were provided with access to water and rodent chow ad libitum, and were housed under a $12 \mathrm{~h} / 12 \mathrm{~h}$ light/dark cycle at $22-24^{\circ} \mathrm{C}$.

Myocardial infarction induction and experimental groups. Initially, all rats were anesthetized with sodium pentobarbitone (40 mg/kg; Sigma-Aldrich) prior to surgery being performed. The myocardial infarction rat model was induced by ligating the left anterior descending coronary artery, as described previously $(20,21)$. The myocardial infarction rat model was confirmed by regional cyanosis of the myocardial surface with measurement of ST-segment elevation.

Briefly, the rats were divided into the following three groups, one group per cage: Control group $(n=10)$, comprising normal rats administered with saline solution $(0.1 \mathrm{ml} / 100 \mathrm{~g})$; vehicle group $(n=10)$, comprising the myocardial infarction rat model administered with saline solution $(0.1 \mathrm{ml} / 100 \mathrm{~g})$; candesartan treatment group $(n=10)$, comprising the myocardial infarction rat model administered with candesartan $0.25 \mathrm{mg} / \mathrm{kg}$ for 2 weeks via the caudal vein, on the basis of the previous report (18). Surgery was performed on the rats in the myocardial infarction group by occlusion of the coronary artery 30 mins following the final administration.

Measurement of the activities of $C K, C K-M B, L D H$ and the level of $c T n T$. Following treatment with candesartan for 2 weeks, whole bloods samples were collected from the rats in each group following occlusion of the coronary artery for $6 \mathrm{~h}$. Subsequently, the supernatants were centrifuged at $12,000 \mathrm{~g}$ for $10 \mathrm{~min}$ at $4^{\circ} \mathrm{C}$ and were stored for subsequent measurement at $-20^{\circ} \mathrm{C}$. According to the manufacturer's instructions (Beyotime Institute of Biotechnology), the activities of CK, CK-MB and LDH, and the level of cTnT in the rats were determined using a suite of commercial kits according to the manufacturer's instructions at $37^{\circ} \mathrm{C}$.

Infarct size measurement. Following treatment with candesartan for 2 weeks, three rats from each group were sacrificed using decollation, then the hearts of the rats were immediately harvested and washed with physiological saline. The hearts of the rats were immediately washed with 


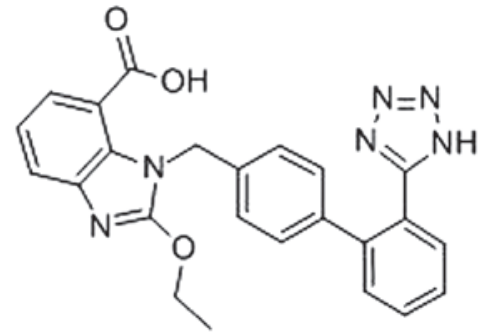

Figure 1. Chemical structure of candesartan.

physiological saline, and the infarct size was measured. The left ventricle was placed at $-80^{\circ} \mathrm{C}$ for $10 \mathrm{~min}$ following ligation of the coronary artery for $6 \mathrm{~h}$. Infarct size was measured following the addition of $1 \%$ 2,3,5-triphenyltetrazolium chloride (1.5\%; Sigma-Aldrich) at $37^{\circ} \mathrm{C}$ for $30 \mathrm{~min}$ in the dark $(22,23)$. The size of the infarct area was measured by the volume and weight, as a percentage of the left ventricle. The heart areas exhibiting a brick red color were considered to be normal myocardium, whereas the areas without color were considered to be ischemic heart muscles.

Western blot analysis of the protein expression levels of $i N O S$ and HSP-72. Following treatment with candesartan for 2 weeks, cardiac cytosolic samples were collected from each group following occlusion of the coronary artery for $6 \mathrm{~h}$. The samples were incubated with $100 \mu \mathrm{l}$ tissue lysis buffer [1\% (w/v) Triton, $0.1 \%$ SDS, $0.5 \%$ deoxycholate, $1 \mathrm{mmol} / 1$ EDTA, $20 \mathrm{mmol} / 1$ Tris ( $\mathrm{pH} 7.4), 150 \mathrm{mmol} / \mathrm{l} \mathrm{NaCl}$, $10 \mathrm{mmol} / \mathrm{l} \mathrm{NaF}$; Beyotime Institute of Biotechnology] for $20 \mathrm{~min}$ on ice. Subsequently, the supernatants were centrifuged at $12,000 \mathrm{~g}$ for $10 \mathrm{~min}$ at $4^{\circ} \mathrm{C}$ and were stored for subsequent measurement at $-20^{\circ} \mathrm{C}$. The protein concentrations were determined using a Bicinchoninic Acid protein assay kit (Sangon Biotech Co., Ltd.). An equal quantity of total protein $(30 \mu \mathrm{g})$ was fractioned on $12 \%$ sodium dodecyl sulfate-polyacrylamide gels (Beyotime Institute of Biotechnology), and transferred electrophoretically onto polyvinylidene fluoride membranes (0.22 mm; EMD Millipore, Billerica, MA, USA). The membranes were blocked with phosphate-buffered saline (PBS) with 5\% non-fat milk to block nonspecific binding sites. Following blocking, the membranes were incubated with monoclonal rabbit anti-human anti-iNOS (1:1,500; cat. no. sc-49055; Santa Cruz Biotechnology, Inc., Dallas, TX, USA), monoclonal rabbit anti-HSP-72 (1:1,000; cat. no. sc-59570; Santa Cruz Biotechnology, Inc.) and monoclonal rabbit anti- $\beta$-actin (1:3,000; cat. no. D110007; Sango Bioscience, Beijing, China) overnight at $4^{\circ} \mathrm{C}$. The following day, the membrane was detected by incubation with sheep anti-rabbit IgG (1:10,000; cat. no. C000944; Sango Bioscience), conjugated with horseradish peroxidase at $37^{\circ} \mathrm{C}$ for $2 \mathrm{~h}$. The relative band intensity was determined using Chem Image 5500 software (UVP, Upland, CA, USA).

ELISA to determine the activities of iNOS and NF- $\kappa B$ p 65. Following treatment with candesartan for 2 weeks, whole bloods samples were collected from the rats in each group, following occlusion of the coronary artery for $6 \mathrm{~h}$. Subsequently, the supernatant were centrifuged at $12,000 \mathrm{x} \mathrm{g}$ for $10 \mathrm{~min}$ at $4^{\circ} \mathrm{C}$ and were stored for subsequent measurement at $-20^{\circ} \mathrm{C}$. According to the manufacturer's instructions (Beyotime Institute of Biotechnology), the activities of iNOS and NF- $\mathrm{BB}$ p65 in the rats were performed using a suite of commercial ELISA kits according to the manufacturer's instructions at $37^{\circ} \mathrm{C}$.

Reverse transcription-quantitative polymerase chain reaction (RT-qPCR) analyses of the gene expression levels of $M C P-1$ and AP-1. Following treatment with candesartan for 2 weeks, cardiac cytosolic samples were collected from each group following occlusion of the coronary artery for $6 \mathrm{~h}$. Total RNA was obtained from the myocardial samples using TRIzol reagent (Invitrogen Life Technologies). RNA (1 $\mu \mathrm{g})$ was reverse transcribed into cDNA using a One Step PrimeScript miRNA cDNA Synthesis kit (Takara Bio, Inc.), according to the manufacturer's instructions. The gene expression levels of MCP-1 and AP-1 were measured by RT-qPCR using a CFX96 Touch Real-Time PCR system (Bio-Rad Laboratories, Inc., Hercules, CA, USA) and a PrimeScript RT reagent kit, according to manufacturer's instructions. The sequences of the AP-1 primers were as follows: Forward 5'-AACTGAAGCTCGCAC TCTCG-3' and reverse 5'-TCAGCACAGATCTCCTTGGC-3'. The sequences of the MCP-1 primers were as follows: Forward 5'-AAGTGTGATGACTCAGGTTTGCCCTGA-3' and reverse 5'-AAGTGTGATATCTCAGGT TTGCCCTGA-3'. The GAPDH primer sequences were as follows: Forward 5'-GCA CCGTCAAGGCTGAGAAC-3' and reverse 5'-TGGTGAAGA CGCCAGTGGA-3'. The reaction was conducted with the following conditions: $95^{\circ} \mathrm{C}$ for $5 \mathrm{~min}, 40$ cycles of $95^{\circ} \mathrm{C}$ for $30 \mathrm{sec}, 60^{\circ} \mathrm{C}$ for $30 \mathrm{sec}$ and $72^{\circ} \mathrm{C}$ for $30 \mathrm{sec}$.

Measurement of caspase-3 and caspase-9 activities. Following treatment with candesartan for 2 weeks, cardiac cytosolic samples were collected from the rats in each group following occlusion of the coronary artery for $6 \mathrm{~h}$. A total of $50 \mu \mathrm{g}$ protein was incubated in solution buffer (Ac-DEVD-pNA for caspase-3; Ac-LEHD-pNA for caspase-9; BD Biosciences, San Jose, CA, USA) at $37^{\circ} \mathrm{C}$ for $30 \mathrm{~min}$ in the dark. According to the manufacturer's instructions (Sangon Biotech Co., Ltd.), the activities of caspase- 3 and caspase- 9 were measured at an absorbance of $405 \mathrm{~nm}$ using a Bio-Rad 680 microplate reader (Bio-Rad Laboratories, Inc.).

Statistical analysis. All data were analyzed using SPSS 17.0 software (SPSS, Inc., Chicago, IL, USA) and are presented as the mean \pm standard deviation. Statistical analyses were performed using one-way analysis of variance, followed by Dunnett's test. $\mathrm{P}<0.05$ was considered to indicate a statistically significant difference.

\section{Results}

Candesartan suppresses the activities of $C K, C K-M B$ and $L D H$, and the level of cTnT in a rat model of acute myocardial infarction. To determine the protective effects of candesartan on the heart of the acute myocardial infarction rat model, the present study examined the activities of CK, CK-MB and $\mathrm{LDH}$, and the level of cTnT in a rat model of acute myocardial infarction. The measurements of serum levels of CK, CK-MB, 
Table I. Candesartan suppresses the activities of CK, CK-MB and LDH, and the level of cTnT in a rat model of myocardial infarction.

\begin{tabular}{llccc}
\hline Group & CK $(\mathrm{U} / \mathrm{ml})$ & CK-MB $(\mathrm{IU} / \mathrm{l})$ & LDH $(\mathrm{U} / \mathrm{l})$ & cTnT $(\mathrm{U} / \mathrm{ml})$ \\
\hline Control & $0.24 \pm 0.02$ & $86.74 \pm 6.83$ & $1711.14 \pm 353.58$ & $0.08 \pm 0.03$ \\
Vehicle & $0.91 \pm 0.05^{\mathrm{a}}$ & $205.39 \pm 9.32^{\mathrm{a}}$ & $5854.12 \pm 431.04^{\mathrm{a}}$ & $0.57 \pm 0.05^{\mathrm{a}}$ \\
CAN $(0.25)$ & $0.43 \pm 0.03^{\mathrm{b}}$ & $112.38 \pm 7.56^{\mathrm{b}}$ & $3252.37 \pm 326.77^{\mathrm{b}}$ & $0.25 \pm 0.03^{\mathrm{b}}$ \\
\hline
\end{tabular}

Data are presented as the mean \pm standard deviation. ${ }^{\mathrm{a}} \mathrm{P}<0.01$, vs. control group; ${ }^{\mathrm{b}} \mathrm{P}<0.01$, vs. vehicle group. Control, saline-treated normal rats; Vehicle, saline-treated infarction model rats; CAN $(0.25)$, candesartan $(0.25 \mathrm{mg} / \mathrm{kg})$-treated infarction model rats.

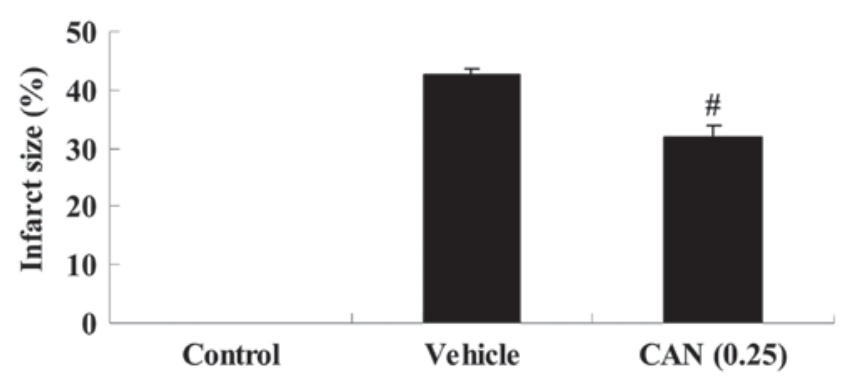

Figure 2.Candesartan suppresses infarct size in an acute myocardial infarction rat model. Data are presented as the mean \pm standard deviation. ${ }^{\#} \mathrm{P}<0.01$, vs. vehicle group. Control, saline-treated normal rats; Vehicle, saline-treated infarction model rats; CAN $(0.25)$, candesartan $(0.25 \mathrm{mg} / \mathrm{kg})$-treated infarction model rats.

LDH and cTnT in the control group, vehicle group and candesartan treatment group $(0.25 \mathrm{mg} / \mathrm{kg})$ are summarized in Table I. The activities of CK, CK-MB and LDH, and the level of cTnT were significantly increased in the serum of the vehicle group, compared with the control group. Pretreatment with candesartan at a dose of $0.25 \mathrm{mg} / \mathrm{kg}$ markedly reduced the activities of CK, CK-MB and LDH, and the level of cTnT in the serum of the rat model of acute myocardial infarction, compared with that in the vehicle group (Table I).

Candesartan suppresses infarct size in a rat model of acute myocardial infarction. The infarct size in the vehicle group was $42.56 \pm 1.23 \%$. Following treatment with candesartan $(0.25 \mathrm{mg} / \mathrm{kg})$, the infarct size of the acute myocardial infarction group was significantly reduced to $31.89 \pm 2.11 \%$, compared with the vehicle group (Fig. 2).

Candesartan inhibits the expression and activity of iNOS in a rat model of acute myocardial infarction. To more directly determine whether candesartan $(0.25 \mathrm{mg} / \mathrm{kg})$ inhibited nitric oxide in the rat model of acute myocardial infarction, the protein expression of iNOS in the rat model of acute myocardial infarction was evaluated using western blot analysis in the present study. The protein expression of iNOS in the vehicle group was significantly increased in the rat model of acute myocardial infarction, compared with the control group (Fig. 3A and B). However, following treatment with candesartan at a dose of $0.25 \mathrm{mg} / \mathrm{kg}$, a marked reduction in the protein expression of iNOS was noted in the rat model of acute myocardial infarction, compared with that in the vehicle
A
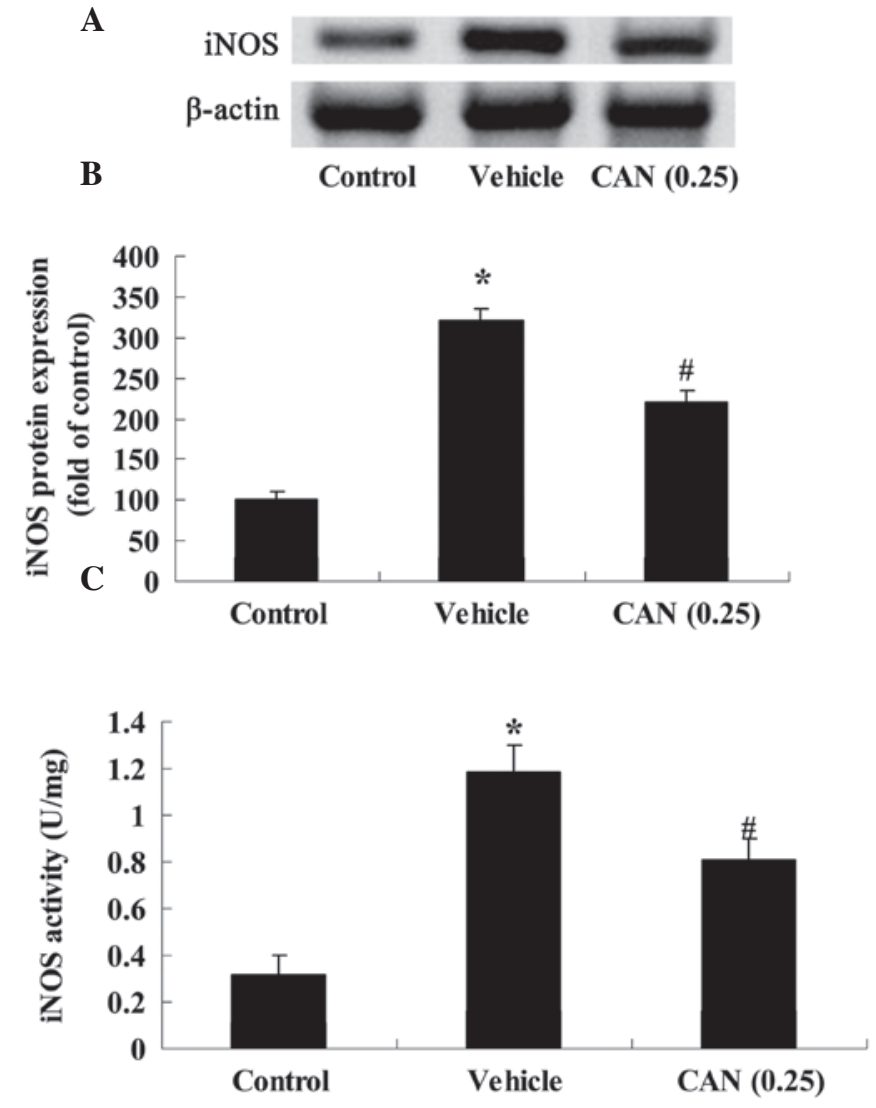

Figure 3. Candesartan inhibits the expression and activity of iNOS in a rat model of acute myocardial infarction. (A) Protein expression of iNOS was measured using western blot analysis. (B) Statistical analysis of protein levels of iNOS. (C) Statistical analysis of the activity of iNOS. Data are presented as the mean \pm standard deviation. ${ }^{*} \mathrm{P}<0.01$, vs. control group; ${ }^{*} \mathrm{P}<0.01$, vs. vehicle group. Control, saline-treated normal rats; Vehicle, saline-treated infarction model rats; CAN $(0.25)$, candesartan $(0.25 \mathrm{mg} / \mathrm{kg})$-treated infarction model rats; iNOS, inducible nitric oxide synthase.

group (Fig. 3A and B). In addition, the activity of iNOS in the vehicle group was markedly elevated, compared with the control group (Fig. 3C). In the candesartan treatment groups $(0.25 \mathrm{mg} / \mathrm{kg})$, the activity of iNOS was significantly decreased, compared with that in the control group (Fig. 3C).

Candesartan inhibits the activity of $N F-\kappa B$ in a rat model of acute myocardial infarction. In order to corroborate the protection of candesartan on NF- $\kappa$ B p65 activity in a rat model of acute myocardial infarction, the activity of NF- $\kappa \mathrm{B}$ p65 in the 


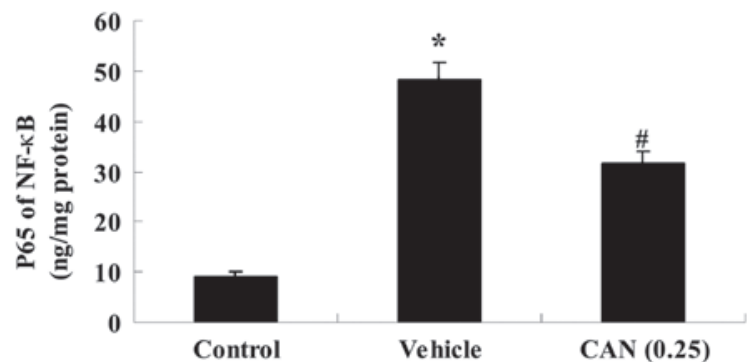

Figure 4. Candesartan inhibits the expression of NF- $\kappa \mathrm{B}$ in a rat model of acute myocardial infarction. Data are presented as the mean \pm standard deviation. ${ }^{*} \mathrm{P}<0.01$, vs. control group; ${ }^{*} \mathrm{P}<0.01$, vs. vehicle group. Control, saline-treated normal rats; Vehicle, saline-treated infarction model rats; CAN $(0.25)$, candesartan $(0.25 \mathrm{mg} / \mathrm{kg})$-treated infarction model rats; NF- $\mathrm{kB}$, nuclear factor $\kappa \mathrm{B}$.

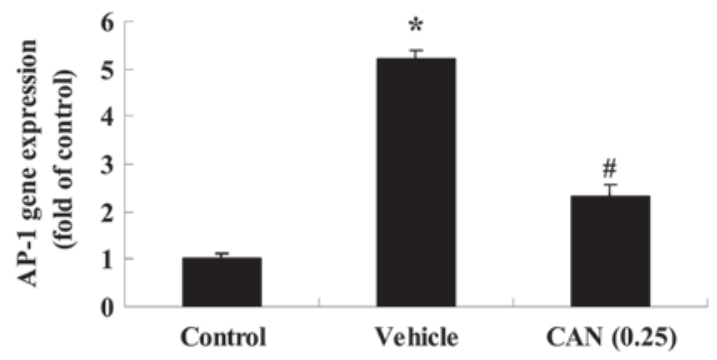

Figure 5. Candesartan inhibits the expression of AP-1 in a rat model of acute myocardial infarction. Data are presented as the mean \pm standard deviation ${ }^{\text {}} \mathrm{P}<0.01$, vs. control group; ${ }^{*} \mathrm{P}<0.01$, vs. vehicle group. Control, saline-treated normal rats; Vehicle, saline-treated infarction model rats; CAN (0.25), cande$\operatorname{sartan}(0.25 \mathrm{mg} / \mathrm{kg})$-treated infarction model rats; AP-1, activating protein-1.

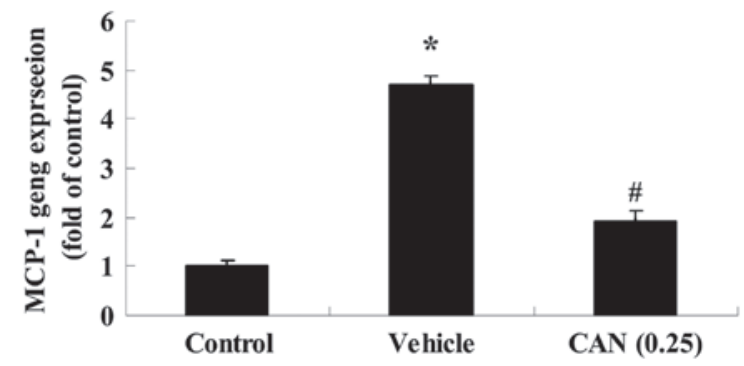

Figure 6. Candesartan inhibits the expression of MCP-1 in a rat model of acute myocardial infarction. Data are presented as the mean \pm standard deviation. ${ }^{*} \mathrm{P}<0.01$, vs. control group; ${ }^{\text {}} \mathrm{P}<0.01$, vs. vehicle group. Control, saline-treated normal rats; Vehicle, saline-treated infarction model rats; CAN (0.25), candesartan (0.25 mg/kg)-treated infarction model rats; MCP-1, monocyte chemotactic protein-1

rat model of acute myocardial infarction was determined using a commercial ELISA kit. The results demonstrated that the activity of NF- $\mathrm{B}$ p 65 in the vehicle group increased, compared with the control group (Fig. 4). Notably, treatment with candesartan $(0.25 \mathrm{mg} / \mathrm{kg})$ reversed the effects of increased $\mathrm{NF}-\kappa \mathrm{B}$ p65 activity, which were observed in the vehicle group (Fig. 4).

Candesartan inhibits the expression of AP-1 in a rat model of acute myocardial infarction. The present study aimed to investigate whether candesartan $(0.25 \mathrm{mg} / \mathrm{kg})$ had protective effects on the expression of AP-1 in the rat model of acute
$\mathbf{A}$

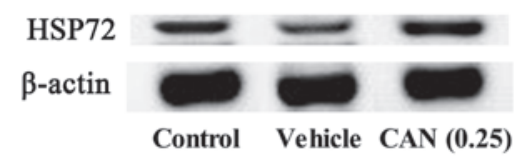

B

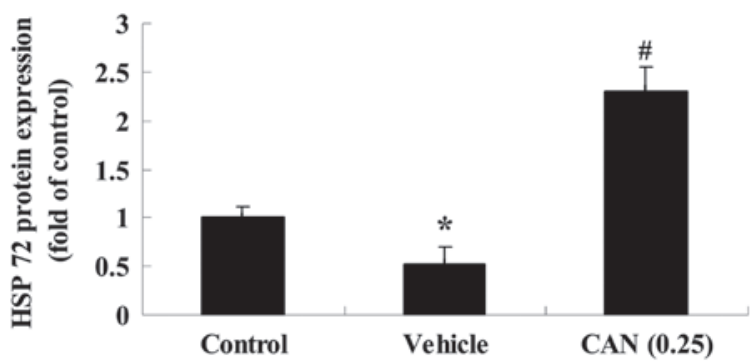

Figure 7. Candesartan restores the expression of HSP-72 in a rat model of acute myocardial infarction. (A) Protein expression level of HSP-72 was measured using western blot analysis. (B) Statistical analysis of protein levels of HSP-72. Data are presented as the mean \pm standard deviation. ${ }^{*} \mathrm{P}<0.01$, vs. control group; ${ }^{\#} \mathrm{P}<0.01$, vs. vehicle group. Control, saline-treated normal rats; Vehicle, saline-treated infarction model rats; CAN (0.25), candesartan $(0.25 \mathrm{mg} / \mathrm{kg})$-treated infarction model rats; HSP-72, heat shock protein-72.

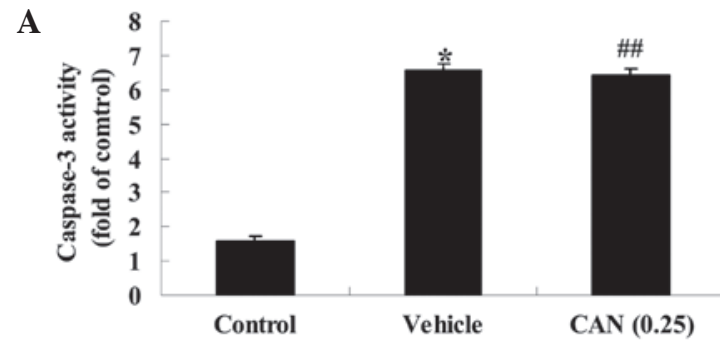

B

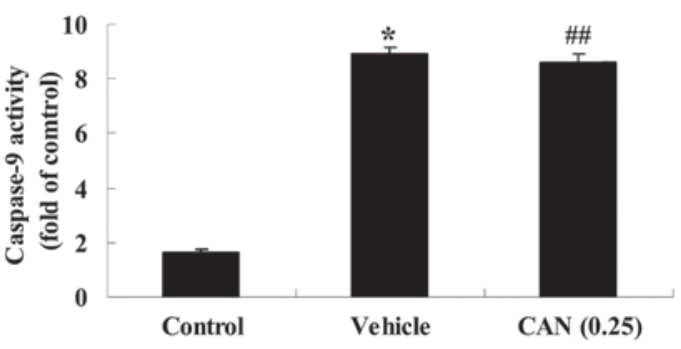

Figure 8. Effects of candesartan on the levels of caspase- 3 and caspase- 9 in a rat model of acute myocardial infarction. The activities of (A) caspase- 3 and (B) caspase-9 were determined in the different treatment groups. Data are presented as the mean \pm standard deviation. ${ }^{*} \mathrm{P}<0.01$, vs. control group; ${ }^{\# \#} \mathrm{P}>0.05$, vs. vehicle group. Control, saline-treated normal rats; Vehicle, saline-treated infarction model rats; CAN $(0.25)$, candesartan $(0.25 \mathrm{mg} / \mathrm{kg})$-treated infarction model rats.

myocardial infarction, The present study examined the gene expression of AP-1 using RT-qPCR. In the left ventricle, the gene expression of AP-1 in the vehicle group was markedly elevated, compared with that in the control group (Fig. 5). Ppretreatment with candesartan $(0.25 \mathrm{mg} / \mathrm{kg})$ was observed to reduce the gen expression of AP-1, compared with that in the vehicle group (Fig. 5).

Candesartan inhibits the expression of MCP-1 in a rat model of acute myocardial infarction. The present study further analyzed 
the protective effects of candesartan on the activity of MCP-1 in the rat model of acute myocardial infarction, by determining the gene expression levels of MCP-1 using RT-qPCR. In the vehicle group, the gene expression of MCP-1 was remarkably increased, compared with that in the control group (Fig. 6). However, following treatment with candesartan $(0.25 \mathrm{mg} / \mathrm{kg})$ for 2 weeks, the gene expression of MCP-1 was decreased significantly, compared with that in the vehicle group (Fig. 6).

Candesartan restores the expression of HSP-72 in a rat model of acute myocardial infarction. To more directly determine whether candesartan restores the expression of HSP-72 in a rat model of acute myocardial infarction, the protein expression of HSP-72 was determined using western blot analysis the present study. The protein expression of HSP-72 in the vehicle group was markedly decreased, compared with that in the control group (Fig. 7A and B). By contrast, pretreatment with candes$\operatorname{artan}(0.25 \mathrm{mg} / \mathrm{kg})$ increased the protein expression of HSP-72, compared with that in the vehicle group (Fig. 7A and B).

Candesartan alters the activities of caspase-3 and caspase- 9 in a rat model of acute myocardial infarction. To investigate the mechanism of candesartan on acute myocardial infarction, the activities of caspase- 3 and caspase- 9 were examined using colorimetric kits in the present study. The activities of caspase- 3 and caspase- 9 in the vehicle group were markedly increased, compared with those in the control group (Fig. 8A and B). However, these activities were not altered following treatment with candesartan $(0.25 \mathrm{mg} / \mathrm{kg})$ in the candesartan treatment group, compared with the vehicle group (Fig. 8A and B).

\section{Discussion}

With economic developments in society and the improvement of living standards, more individuals are being found to exhibit high blood pressure, high cholesterol and high blood sugar, and patients with angina pectoris and myocardial infarction are also following an increasing trend (24). The irreversible necrosis caused by myocardial ischemic myocardial disease results in repeated episodes of heart failure, which is the leading cause of mortality worldwide (25). In the present study, the activities of CK, CK-MB and LDH, and the level of cTnT were observed to increase in the serum of a rat model of acute myocardial infarction following candesartan $(0.25 \mathrm{mg} / \mathrm{kg})$ treatment. In addition, the size of the acute myocardial infarction was significantly reduced in these rats. Suzuki et al reported that candesartan is more effective than angiotensin-converting enzyme inhibitors in preventing left ventricular remodeling following acute myocardial infarction (26).

There are two types of NOS for endothelial cells and cardiomyocytes: Primary NOS of calcium/calmodulin-dependence and iNOS of calcium/calmodulinnon-dependence (27). Endothelial cells synthesize a small quantity of nitric oxide under physiological conditions by primary NOS, which is important in the diffusion of nitric oxide into vascular smooth muscle cells, vascular relaxation through cyclic guanosine monophosphate pathway; entering the bloodstream to inhibit the activation, adhesion and aggregation of platelets and leukocytes; reducing the generation of superoxide radicals through direct inhibition of reduced nicotinamide adenine dinucleotide phosphate oxidase in neutrophils; and regulating the expression of adhesion molecules in neutrophils and endothelial cells (28). Following acute myocardial infarction, the basic function of coronary artery endothelial cells and the release function of nitric oxide stimulation by acetylcholine are impaired, and neutrophil-endothelial cell adhesion is promoted. The present study found that the protein expression and activity of iNOS were significantly reduced in a rat model of acute myocardial infarction. Bian et al reported the association between the effects of candesartan and NOS in spontaneous hypertensive rats (29), and Miller et al identified that candesartan attenuates diabetic retinal vascular pathology by the reduction of iNOS (30).

$\mathrm{NF}-\kappa \mathrm{B}$ has a central regulatory role in a variety of tissue and organ injuries (31). As a nuclear transcription factor with multi-directional regulation effect, $\mathrm{NF}-\kappa \mathrm{B}$ regulates the expression of a number of important immune factors, and may be involved in the promotion of inflammatory cytokine and chemokine generation, the proliferation differentiation of fibroblasts, extracellular matrix crosslinking and apoptosis, and is involved in the process of acute myocardial infarction, promoting the progression of acute myocardial infarction disease $(7,32,33)$. Therefore its role in the development of acute myocardial infarction cannot be ignored. In the present study, candesartan was observed to attenuate NF- $\mathrm{NB}$ p65 activity in the rat model of acute myocardial infarction. Furthermore, Hadi et al reported that candesartan significantly attenuates atherosclerotic lesions and significantly reduces $\mathrm{NF}-\kappa \mathrm{B}$ activity in rabbits (34). In addition, Ishrat et al demonstrated that candesartan reduces hemorrhage in rat embolic stroke through a reduction in $\mathrm{NF}-\kappa \mathrm{B}$ activity (35).

MCP-1 is a chemokine of CC-type cells, involved as signaling molecules. There are $\mathrm{NF}-\kappa \mathrm{B}$ and $\mathrm{AP}-1$ binding sites in the gene promoter site, which can be combined with the DNA binding sequence of $N F-\kappa B$, thus activating the transcription of the gene. Experiments have demonstrated that MCP-1 can protect neonatal myocardial cells of mice from hypoxic death, and its cytoprotective and chemotaxis effects are achieved through different signaling mechanisms. In the present study, the gene expression of MCP-1 was decreased by candesartan treatment. Candesartan has also been observed to inhibit LPS-induced gene expression through the suppression of MCP-1 protein concentrations in human renal tubular epithelial cells (36). Hadi et al reported that candesartan retards the progression of atherosclerosis via reducing MCP-1, $\mathrm{NF}-\kappa \beta$ and oxidative pathways (34).

The AP-1 transcription factor is an important target of intracellular c-Jun N-terminal kinase/stress-activated protein kinase protein products, encoded by immediate early genes in the nucleus, c-fos and c-Jun, from Fos and Jun family proteins respectively, which form homogenous or heterogeneous dimers through combination in a leucine zipper structure, to constitute the AP-1 transcription factor (11). The results of the present study demonstrated that candesartan reduced the gene expression of AP-1 in a rat model of acute myocardial infarction. Tharaux et al indicated that AP-1-receptor antagonism by candesartan activates the collagen I gene through the mitogen-acitvated protein/extracellular-signal regulated kinase pathway (37). 
Previous studies have reported that HSP70 is an important cardioprotective protein, which is involved in delayed myocardial protection. $(38,39)$ It has been demonstrated that heat shock for $24 \mathrm{~h}$ can increase myocardial tolerance to I/R injury, manifested by a reduction in infarct size (18). There are two types of method known to increase HSP72 content in cardiomyocytes. The first is the induction of the endogenous expression of HSP72, usually realized by heat stress at sublethal doses or by other harmful stimulating factors, including ischemia, hypoxia, ethanol, heavy metal salts and infection (40). The second is to guide exogenous HSP70 genes, to increase the expression levels of cardiac HSP72 by transgenic technology (11). The present study demonstrated that candesartan increased the protein expression of HSP-72 in a rat model of acute myocardial infarction. Taniguchi et al also suggested that candesartan protects against reperfusion injury in hereditary insulin-resistant rats through recovery of the expression of HSP72 (18).

Previous studies have revealed that candesartan improves peak systolic pressure, however, it does not alter the level of apoptosis or the expression of caspase-3 (41-43). Therefore, the present study examined the association between the protective effect of candesartan on acute myocardial infarction and the apoptosis of myocardial cells. In the present study, candesartan had no affect on cell apoptosis in acute myocardial infarction, or on the activities of caspase- 3 and caspase- 9 in the rat model of acute myocardial infarction. These results indicated that the protective effect of candesartan on acute myocardial infarction may involve several pathways. In conclusion, the present study demonstrated that the protective effect of candesartan ameliorated acute myocardial infarction in rats and revealed that its activity regulated iNOS, $\mathrm{NF}-\kappa \mathrm{B}$, MCP-1, AP-1 and HSP72 in the rat model of acute myocardial infarction. Further investigations are required to clarify the other key signaling pathways of the interaction between the protective effect of candesartan and acute myocardial infarction.

Further investigations are required to clarify the other signaling pathways underlying the interaction between the protective effects of candesartan and acute myocardial infarction for clinical application.

\section{Acknowledgements}

This study was supported by the Key Program of the National Natural Science Foundation of China (grant no. 30830051), the ' 13315 ' Scientific and Technological Innovation Project of Shaanxi Province (grant no. 2008ZDKG-62) and the Scientific and Technological Projects for Social Development of Shaanxi Province (grant no. 2015SF024).

\section{References}

1. Zhong J, He Y, Chen W, Shui X, Chen C and Lei W: Circulating microRNA-19a as a potential novel biomarker for diagnosis of acute myocardial infarction. Int J Mol Sci 15: 20355-20364, 2014.

2. Zhao YJ, Fu XH, Ma XX, Wang DY, Dong QL, Wang YB, Li W, Xing $\mathrm{K}, \mathrm{Gu} \mathrm{XS}$ and Jiang YF: Intracoronary fixed dose of nitro6 prusside via thrombus aspiration catheter for the prevention of the no-reflow phenomenon following primary percutaneous coronary intervention in acute myocardial infarction. Exp Ther Med 6: 479-484, 2013.
3. Gui D, Li Y, Chen X, Gao D, Yang Y and Li X: HIF1 signaling pathway involving iNOS, COX2 and caspase- 9 mediates the neuroprotection provided by erythropoietin in the retina of chronic ocular hypertension rats. Mol Med Rep 11: 1490-1496, 2015.

4. Liu X and Tao GZ: Effects of tirofiban on the reperfusion-related no-reflow in rats with acute myocardial infarction. J Geriatr Cardiol 10: 52-58, 2013.

5. Zaitone SA and Abo-Gresha NM: Rosuvastatin promotes angiogenesis and reverses isoproterenol-induced acute myocardial infarction in rats: Role of iNOS and VEGF. Eur J Pharmacol 691: 134-142, 2012.

6. Xiong HY, Ma TT, Wu BT, Lin Y and Tu ZG: IL-12 regulates B7-H1 expression in ovarian cancer-associated macrophages by effects on NF-kB signalling. Asian Pac J Cancer Prev 15: 5767-5772, 2014

7. Sui $\mathrm{X}$ and Gao C: Huperzine A ameliorates damage induced by acute myocardial infarction in rats through antioxidant, anti-apoptotic and anti-inflammatory mechanisms. Int J Mol Med 33: 227-233, 2014.

8. Qiao S, Xie H, Wang C, Wu X, Liu H and Liu C: Delayed anesthetic preconditioning protects against myocardial infarction via activation of nuclear factor-kB and upregulation of autophagy. J Anesth 27: 251-260, 2013

9. Tang M, Wang Y, Han S, Guo S, Xu N and Guo J: Endogenous PGE(2) induces MCP-1 expression via EP4/p38 MAPK signaling in melanoma. Oncol Lett 5: 645-650, 2013.

10. Martin T, Cardarelli PM, Parry GC, Felts KA and Cobb RR: Cytokine induction of monocyte chemoattractant protein-1 gene expression in human endothelial cells depends on the cooperative action of NF-kappa B and AP-1. Eur J Immunol 27: 1091-1097, 1997.

11. Valen G, Hansson GK, Dumitrescu A and Vaage J: Unstable angina activates myocardial heat shock protein 72 , endothelial nitric oxide synthase, and transcription factors NFkappaB and AP-1. Cardiovasc Res 47: 49-56, 2000.

12. Xie SL, Wang JF, Nie RQ, Yuan WL, Li F and Lin YQ: The expression and significance of activator protein-1 and matrix metalloproteinases in the human heart post acute myocardial infarction. Zhonghua Nei Ke Za Zhi 48: 205-207, 2009 (In Chinese).

13. Tanonaka K, Toga W, Yoshida H, Furuhama K and Takeo S: Effect of long-term treatment with trandolapril on Hsp72 and Hsp73 induction of the failing heart following myocardial infarction. Br J Pharmacol 134: 969-976, 2001.

14. Marunouchi T, Araki M, Murata M, Takagi N and Tanonaka K: Possible involvement of HSP90-HSF1 multichaperone complex in impairment of HSP72 induction in the failing heart following myocardial infarction in rats. J Pharmacol Sci 123: 336-346, 2013.

15. Gholitabar S and Roshan VD: Effect of treadmill exercise and Ferula gummosa on myocardial HSP72, vascular function, and antioxidant defenses in spontaneously hypertensive rats. Clin Exp Hypertens 35: 347-354, 2013.

16. Songur CM, Songur MO, Kocabeyoglu SS and Basgut B: Effects of the AT1 receptor blocker candesartan on myocardial ischemia/reperfusion in isolated rat hearts. Heart Surg Forum 17: E263-E268, 2014.

17. Jusufovic M, Sandset EC, Bath PM and Berge E; Scandinavian Candesartan Acute Stroke Trial Study Group: Blood pressure-lowering treatment with candesartan in patients with acute hemorrhagic stroke. Stroke 45: 3440-3442, 2014.

18. Taniguchi Y, Takahashi N, Fukui A, Nagano-Torigoe Y, Thuc LC, Teshima Y, Shinohara T, Wakisaka O, Ooie T, Murozono Y, et al: Candesartan restored cardiac Hsp72 expression and tolerance against reperfusion injury in hereditary insulin-resistant rats. Cardiovasc Res 92: 439-448, 2011.

19. Marx JO, Brice AK, Boston RC and Smith AL: Incidence rates of spontaneous disease in laboratory mice used at a large biomedical research institution. J Am Assoc Lab Anim Sci 52: 782-791, 2013.

20. Faria Tde O, Baldo MP, Simões MR, Pereira RB, Mill JG, Vassallo DV and Stefanon I: Body weight loss after myocardial infarction in rats as a marker of early heart failure development. Arch Med Res 42: 274-280, 2011.

21. Zeng KW, Zhang T, Fu H, Liu GX and Wang XM: Schisandrin B exerts anti-neuroinflammatory activity by inhibiting the Toll-like receptor 4-dependent MyD88/IKK/NF-kB signaling pathway in lipopolysaccharide-induced microglia. Eur J Pharmacol 692: 29-37, 2012. 
22. Hoda MN, Li W, Ahmad A, Ogbi S, Zemskova MA, Johnson MH, Ergul A, Hill WD, Hess DC and Sazonova IY: Sex-independent neuroprotection with minocycline after experimental thromboembolic stroke. Exp Transl Stroke Med 3: 16, 2011.

23. Hoda MN, Siddiqui S, Herberg S, Periyasamy-Thandavan S, Bhatia K, Hafez SS, Johnson MH, Hill WD, Ergul A, Fagan SC and Hess DC: Remote ischemic perconditioning is effective alone and in combination with intravenous tissue-type plasminogen activator in murine model of embolic stroke. Stroke 43: 2794-2799, 2012.

24. Lv P, Zhou M, He J, Meng W, Ma X, Dong S, Meng X, Zhao X, Wang $X$ and He F: Circulating miR-208b and miR-34a are associated with left ventricular remodeling after acute myocardial infarction. Int J Mol Sci 15: 5774-5788, 2014.

25. Lee SR, Noh SJ, Pronto JR, Jeong YJ, Kim HK, Song IS, Xu Z, Kwon HY, Kang SC, Sohn EH, et al: The critical roles of zinc: Beyond impact on myocardial signaling. Korean J Physiol Pharmacol 19: 389-399, 2015.

26. Suzuki H, Kusuyama T, Omori Y, Soda T, Tsunoda F, Sato T, Shoji M, Iso Y, Kondo T, Koba S, et al: Inhibitory effect of candesartan cilexetil on left ventricular remodeling after myocardial infarction. Int Heart J 47: 715-725, 2006.

27. Jiang P, Li C, Xiang Z and Jiao B: Tanshinone IIA reduces the risk of Alzheimer's disease by inhibiting iNOS, MMP-2 and NF-kBp65 transcription and translation in the temporal lobes of rat models of Alzheimer's disease. Mol Med Rep 10: 689-694, 2014.

28. Lee KF, Chen JH, Teng CC, Shen CH, Hsieh MC, Lu CC, Lee KC, Lee LY, Chen WP, Chen CC, et al: Protective effects of Hericium erinaceus mycelium and its isolated erinacine A against ischemia-injury-induced neuronal cell death via the inhibition of iNOS/p38 MAPK and nitrotyrosine. Int J Mol Sci 15: 15073-15089, 2014.

29. Bian SH, Yu MY and Geng Q: The relationship between the plasma concentration of urotension II (U II) and NO, NOS in spontaneous hypertensive rats and influence of candesartan. Zhongguo Ying Yong Sheng Li Xue Za Zhi 25: 194-195; 263, 2009 (In Chinese).

30. Miller AG, Tan G, Binger KJ, Pickering RJ, Thomas MC, Nagaraj RH, Cooper ME and Wilkinson-Berka JL: Candesartan attenuates diabetic retinal vascular pathology by restoring glyoxalase-I function. Diabetes 59: 3208-3215, 2010.

31. Wang Y, Ma W and Zheng W: Deguelin, a novel anti-tumorigenic agent targeting apoptosis, cell cycle arrest and anti-angiogenesis for cancer chemoprevention. Mol Clin Oncol 1: 215-219, 2013.

32. Korkmaz S, Atmanli A, Li S, Radovits T, Hegedús P, Barnucz E, Hirschberg K, Loganathan S, Yoshikawa Y, Yasui H, et al Superiority of zinc complex of acetylsalicylic acid to acetylsalicylic acid in preventing postischemic myocardial dysfunction. Exp Biol Med (Maywood) 240: 1247-1255, 2015.
33. Basso C, Calabrese F, Angelini A, Carturan E and Thiene G: Classification and histological, immunohistochemical, and molecular diagnosis of inflammatory myocardial disease. Heart Fail Rev 18: 673-681, 2013.

34. Hadi NR, Yousif NG, Abdulzahra MS, Mohammad BI, Al-Amran FG, Majeed ML and Yousif MG: Role of NF- $\kappa \beta$ and oxidative pathways in atherosclerosis: Cross-talk between dyslipidemia and candesartan. Cardiovasc Ther 31: 381-387, 2013

35. Ishrat T, Pillai B, Ergul A, Hafez S and Fagan SC: Candesartan reduces the hemorrhage associated with delayed tissue plasminogen activator treatment in rat embolic stroke. Neurochem Res 38: 2668-2677, 2013.

36. Zhao LQ, Huang JL, Yu Y, Lu Y, Fu LJ, Wang JL, Wang YD and Yu C: Candesartan inhibits LPS-induced expression increase of toll-like receptor 4 and downstream inflammatory factors likely via angiotensin II type 1 receptor independent pathway in human renal tubular epithelial cells. Sheng Li Xue Bao 65: 623-630, 2013.

37. Tharaux PL, Chatziantoniou C, Fakhouri F and Dussaule JC: Angiotensin II activates collagen I gene through a mechanism involving the MAP/ER kinase pathway. Hypertension 36: 330-336, 2000.

38. Traister A, Walsh M, Aafaqi S, Lu M, Dai X, Henkleman MR, Momen A, Zhou YQ, Husain M, Arab S, et al: Mutation in integrin-linked kinase (ILK(R211A)) and heat-shock protein 70 comprise a broadly cardioprotective complex. PLoS One 8: e77331, 2013

39. Yadav HN, Singh M and Sharma PL: Pharmacological inhibition of GSK-3 $\beta$ produces late phase of cardioprotection in hyperlipidemic rat: Possible involvement of HSP 72. Mol Cell Biochem 369: 227-233, 2012.

40. Torrente MP and Shorter J: The metazoan protein disaggregase and amyloid depolymerase system: Hsp110, Hsp70, Hsp40, and small heat shock proteins. Prion 7: 457-463, 2013.

41. Chen C, Du P and Wang J: Paeoniflorin ameliorates acute myocardial infarction of rats by inhibiting inflammation and inducible nitric oxide synthase signaling pathways. Mol Med Rep 12: 3937-3943, 2015

42. Nural-Guvener HF, Zakharova L, Nimlos J, Popovic S, Mastroeni D and Gaballa MA: HDAC class I inhibitor, Mocetinostat, reverses cardiac fibrosis in heart failure and diminishes CD90+ cardiac myofibroblast activation. Fibrogenesis Tissue Repair 7: 10, 2014.

43. Moudgil R, Musat-Marcu S, Xu Y, Kumar D and Jugdutt BI: Increased AT2R protein expression but not increased apoptosis during cardioprotection induced by AT1R blockade. Can J Cardiol 18: 873-883, 2002. 